\title{
Swedish Female Hairdressers' Views on Their Work Environ- ment-A Qualitative Study
}

\author{
Kerstin Kronholm Diab ${ }^{1}$, Jörn Nielsen ${ }^{1}$ and Edith Andersson ${ }^{2}$ \\ ${ }^{1}$ Division of Occupational and Environmental Medicine, Lund University, Sweden and ${ }^{2}$ Department of Health \\ Sciences, Lund University, Sweden
}

\begin{abstract}
Swedish Female Hairdressers' Views on Their Work Environment-A Qualitative Study: Kerstin KRONHOLM DiAB, et al. Division of Occupational and Environmental Medicine, Lund University, Sweden-Objectives: Hairdressers have several work-related health hazards. Little is known of their strategies for the work environment. The aim of this study was to explore female hairdressers' own views on their physical, social and psychological work environment and possibilities of influencing it, implementation of their knowledge, financial impacts and how workrelated symptoms affect their views. Methods: Fourteen hairdressers working for four years were subjected to open-ended interviews covering aspects of the physical, social and psychological work environment. Content analysis was applied. Results: An awareness of the impact of the work environment and the possibilities of influencing it emerged, but also an inability to achieve preventive improvements. This included reflections concerning ventilation, health issues, job strain, hair products, financial issues, knowledge from school and concern for having to leave the profession. The organization and acceptance of the work environment were important issues. Making the work environment an active part of their business was not common. Conclusions: Female hairdressers had an awareness of their work environment but lacked the means and strategies to make it an active part of their business. The main focus was on the customers and the work techniques. Having various symptoms did not alter this. Organizational and financial issues could put limitations on the work environment. Teachers were crucial in making the work environment interesting. Hairdressing was seen with advantages and disadvantages, and its future was seen as being insecure in terms of the occupational health risks. The hairdressers expressed a great pride in their profession providing possibilities for
\end{abstract}

Received Jul 9, 2013; Accepted Nov 29, 2013

Published online in J-STAGE Jan 16, 2014

Correspondence to: K. K. Diab, Division of Occupational and Environmental Medicine Department of Laboratory Medicine, Lund Lund University, SE-221 85 LUND, Sweden

(e-mail: Kerstin.Diab@med.lu.se) development.

(J Occup Health 2014; 56: 100-110)

Key words: Content analysis, Hairdressing, Health risks, Prevention, Strategies, Work environment

Hairdressers constitute an occupational group whose work has been shown to contain a number of workrelated health risk factors. Studies of the occupation of hairdressing have been performed both nationally and internationally during the last $10-15$ years. A number of articles stem from a Swedish context and concern respiratory symptoms ${ }^{1-4)}$, skin symptoms ${ }^{5,6)}$ and reproduction ${ }^{7-9)}$. Little is, however, known about the strategies that hairdressers use in their work environment to reduce health risk factors and to prevent ill health.

The magnitude of the problem was emphasized when the Swedish Work Environment Authority (SWEA) performed 169 inspections in the sector in the years 2005-200910). More than 700 demands for improvements were reported, concerning risk assessments, policies and routines, chemical health risks and also business premises. Hairdressers reported 292 work-related illnesses during this period, and women reported approximately $90 \%$ of these. Injuries related to physical strain were the most common, but female hairdressers reported more symptoms of allergy and skin hypersensitivity than in any other business field.

Approximately $25 \%$ of the reported work-related illnesses were associated with chemicals, and more than $50 \%$ of these concerned skin diseases. Hairdressers often state that chemicals, such as hair dye and bleaching powder are the cause of skin diseases and allergies ${ }^{10)}$. SWEA also performed an inspection campaign at hairdresser and nail builder salons in 2011 in southern Sweden, which resulted in 1,158 inspections. A total of 1,663 specific demande were noted in 585 reports, of which 1,008 concerned chemical risks ${ }^{11)}$. Statistics Sweden has reported that $23 \%$ of hairdressers had work-related symptoms 
due to difficult working postures in a twelve month period $^{12)}$. These results confirm those from a recent British study of self-reported work-related symptoms in hairdressers showing that they have a greater prevalence of work-related symptoms in the shoulders, wrists, hands and lower and upper back, pain in the legs and feet and work-related coughs and asthma. The authors of the report maintain that professional training for hairdressers must include appropriate health education in addition to health risk assessment ${ }^{13)}$.

Hairdressers in Sweden are an occupational group that is predominantly female $(87 \%)^{12)}$. There were 2,400 workplaces in 2010 where there were one or more employees, and the national average was three employees per workplace. There were also approximately 15,000 active one-person enterprises. Approximately 2,600 students graduated from the different hairdressing programs in 2010 , and $40 \%$ of the hairdressers are still active as hairdressers eight years after completing their education ${ }^{11)}$.

Despite hairdressers having frequent health complaints and occupational symptoms impacting their health-related quality of life (HRQoL) $)^{4}$, there is a lack of studies focusing on hairdressers' views on and strategies concerning their work environment. We thus wanted to study the perceptions of young female Swedish hairdressers regarding their work environment and how they cope with it.

\section{Objectives}

The overall aim was to explore female hairdressers' views on their physical, social and psychological work environment and possibilities of influencing it, implementation of their knowledge, financial impact and how work related symptoms affect their view.

Table 1. Characteristics and respiratory symptoms of the participants $(\mathrm{N}=14)$

\begin{tabular}{llcc}
\hline & & Mean & SD \\
\hline Age & & 22.4 & 0.65 \\
& & N & $\%$ \\
Atopy & 8 & 57 \\
Tobacco & Never smoked & 5 & 36 \\
& Ex smoker & 1 & 7 \\
Hand eczema & Smoker & 8 & 57 \\
Nasal symptoms & & 3 & 21 \\
Throat symptoms & Work related & 9 & 64 \\
Wheeze/ & Work related & 5 & 36 \\
shortness of breath & Work related & 1 & 7 \\
\hline
\end{tabular}

\section{Methods}

A qualitative method was chosen for this study in order to gain subjective experiences and hairdressers' views on their work environment. This is an approach that includes methods for interviewing, analyzing and interpreting the studied phenomenon ${ }^{14}$. The interviewer's pre-understanding was based on earlier research within the hairdressing field concerning female hairdressers' respiratory symptoms ${ }^{1,4,15)}$. The second author had experience from the hairdresser work environment, while the third author had considerable experience of qualitative research methodology.

\section{Data collection}

Fourteen participants from a group of recently graduated female hairdressers who had worked for three to four years were selected. Seven of these had workrelated respiratory symptoms, and seven did not. This division into two subgroups was made based on the nature of the original project, the aim of which was to discover if there were any differences between the two groups of hairdressers. The analysis of the data did not reveal any differences, and thus the results are presented for the whole group. A further ten hairdressers declined to participate due to travelling abroad or too great a work load. The characteristics of the participant hairdressers are provided in Tables 1, 2 and 3.

The data were collected in open interviews taking place in the participants' home or business premises in accordance with their wishes. The first author conducted all the interviews using an interview guide covering the physical, social and psychological work environments. The opening question was, How is your work environment? The interviews were

Table 2. Working hours and working conditions of the participants $(\mathrm{N}=14)$

\begin{tabular}{|c|c|c|c|}
\hline & & Median & Min-Max \\
\hline Working hours & week & 38.3 & $20-50$ \\
\hline Working condi & ions & $\mathrm{N}$ & $\%$ \\
\hline Number of & $1-2$ & 6 & 43 \\
\hline hairdressers/ & $3-4$ & 6 & 43 \\
\hline salon & $6-13$ & 2 & 14 \\
\hline Type of & Self employed & 3 & 21 \\
\hline employment & Renting a chair & 7 & 50 \\
\hline & Employee & 4 & 29 \\
\hline Ventilation & Local air extraction & 2 & 14 \\
\hline & Extra roof ventilation & 7 & 50 \\
\hline & Air condition & 2 & 14 \\
\hline Regular use of & orotective gloves & 14 & 100 \\
\hline
\end{tabular}


Table 3. Hair treatments performed by the participants $(\mathrm{N}=14)$

\begin{tabular}{llcc}
\hline Hair treatments & Times/week & $\mathrm{N}$ & $\%$ \\
\hline Bleaching & $1-2$ & 1 & 7 \\
& $3-5$ & 8 & 57 \\
High lighting blonde & $6-10$ & 5 & 36 \\
& $1-2$ & 7 & 50 \\
Hair dyes & $3-5$ & 3 & 21 \\
& $1-2$ & 1 & 7 \\
& $3-5$ & 7 & 50 \\
& $6-10$ & 3 & 21 \\
Hair spray & $>10$ & 3 & 21 \\
& $3-5$ & 1 & 7 \\
& $6-10$ & 2 & 14 \\
& $>10$ & 11 & 79 \\
\hline
\end{tabular}

performed as an open conversation in which the interviewer probed further by using follow-up questions in order to ensure that the total work environment was covered. The interviews lasted 22-69 minutes and were tape-recorded and transcribed verbatim including pauses and emotional expressions.

\section{Data analysis}

The text was analyzed using a conventional inductive qualitative content analysis. The aim was to gain information from the informants without imposing preconceived categories or theoretical perspectives. The generated findings of the content analysis are based on the participants' unique perspectives and grounded in the data ${ }^{16)}$. Both manifest and latent content analyses were used in this study. The focus in a manifest analysis is on the most obvious meanings in the text, while in a latent content analysis, the text is interpreted in order to discover its deep structural meaning ${ }^{14)}$. In this study, we present the manifest and the latent findings in an integrated way.

The analysis started with the first and the third authors reading and re-reading the interviews independently in order to achieve immersion and obtain a sense of the whole. The authors then discussed their impressions of the text and decided on a structure for the analysis. Meaning units related to the aim of the study were identified and collated. The meaning units were re-read and coded according to the content of the text. Codes of similar content were then grouped and labelled as themes and subthemes. The statements in each theme were analyzed critically and questioned, read and compared. In the last step, the themes were compared with the original text and with each other in a constant movement between the whole and the parts and between the text and the themes, and a main theme was determined ${ }^{17)}$. The first and third authors were both involved in the process of development of the themes and subthemes.

The credibility of the results was addressed through critical judgment in which the first and third authors took an active part in the data analysis, and this was discussed thoroughly in the process leading to refinement of the themes and subthemes. The second author did not take an active part in analysis of all the interviews but agreed on the themes after having read a number of the interviews.

\section{Ethical considerations}

After providing them with written and oral information, informed consent was obtained from the participants, who could withdraw from the study at any time; these procedures were performed in accordance with the principals of research ethics and approved by the Regional Ethical Review Board in Lund (Dnr 2009/98, 838/2005).

\section{Findings}

Awareness of the impact of the work environment and of possibilities to influence it

The overall interpretation revealed different levels of awareness of the influence of the work environment on the hairdressers and of the possibilities for them to influence it but also revealed an inability to achieve the desired preventive improvements. The awareness included reflections concerning ventilation, respiratory, skin and ergonomic issues, job strain, choice of hair products, financial issues and concern for having to leave the profession as well as for their approach to working with the work environment. Furthermore, the organization of the enterprise and acceptance of the work environment were important emerging issues. Making the work environment an active part of their business was not a chosen strategy, and the means were not always there. The themes in the findings were seeing one's work environment, seeing one's customers, seeing one's profession, seeing one's symptoms, and managing one's waste. The latter was only linked with seeing one's work environment, while all the others were linked with each other (Fig. 1). From the overall interpretation, a main theme and integrated themes emerged and are shown in Fig. 1; Table 4 shows the subthemes. These are further described below with illustrative quotations from the interviews.

\section{Seeing one's work environment}

The work environment was fundamental for the hairdressers in many respects, and most of the hairdressers spoke of the possibility of perhaps not being able to continue in the profession for the whole of their working lives. There was an awareness of the 


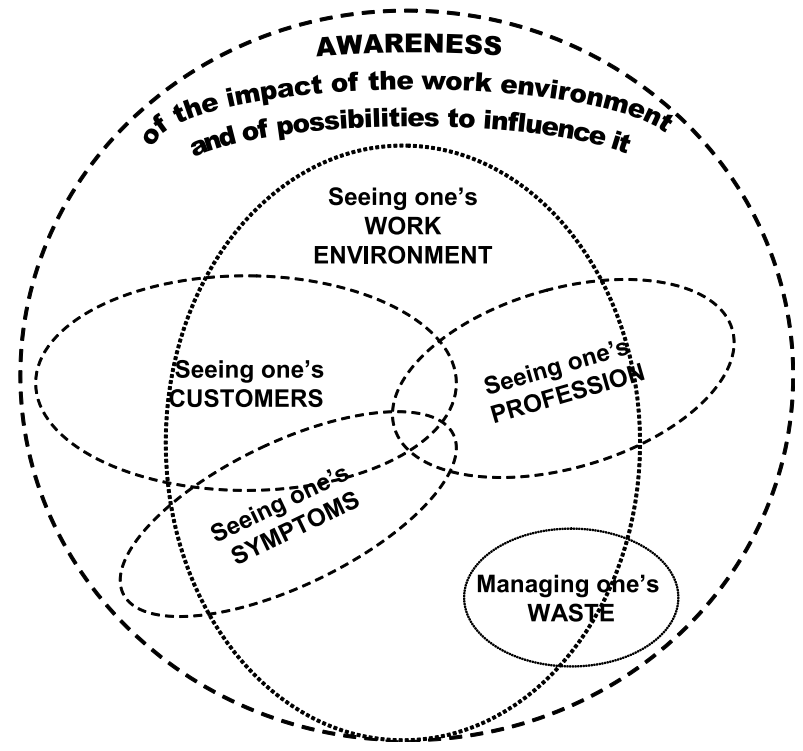

Fig. 1. The hairdresser's views on their work environment.

advantages and disadvantages in the work, of the possibilities of influencing the work environment, of applying knowledge and of being able to plan the work to a greater or lesser extent. Seeing one's work environment was described as influencing the work environment, applying knowledge and planning work.

1) Influencing the work environment

There was an awareness of the need for measures to prevent illness due to the work environment, but the hairdressers often failed to take steps to make improvements because of a number of factors. Acceptance of the work environment itself and the existence of symptoms was extensive, but there was often a lack of awareness as to which preventive actions should be taken. Some hairdressers tried, however, to find solutions to the problems. The financial situation and the organization of the salon were also important factors; for example, major financial investments would be difficult to make for those hairdressers who rented a chair and were not the owner of the salon, which was the most common organizational solution. The responsibility for the premises and the equipment would then be in the hands of others. Other strategies, for example, changes in work technique or physical training, were then employed, or the situation was accepted as one that could not be influenced.

"Yes, but it's important, it is. Your work environment has a lot to do with how long you can work, particularly in this profession, where there are so many who don't work until their pension. There are so many injuries and a lot of allergies and such. It's very important." [Interview person (Ip) 8]
Table 4. Interpretation of the hairdressers' work environment

AWARENESS of the impact of the work environment and of possibilities to influence it.

\begin{tabular}{|c|c|}
\hline Themes & Subthemes \\
\hline \multirow[t]{3}{*}{$\begin{array}{l}\text { Seeing one's work } \\
\text { environment }\end{array}$} & $\begin{array}{l}\text { Influencing the work environ- } \\
\text { ment }\end{array}$ \\
\hline & Applying knowledge \\
\hline & Planning work \\
\hline \multirow[t]{2}{*}{ Seeing one's customers } & $\begin{array}{l}\text { Adjusting to the customer's } \\
\text { needs }\end{array}$ \\
\hline & Caring for the customer \\
\hline \multirow[t]{2}{*}{ Seeing one's profession } & $\begin{array}{l}\text { Developing and continuing in } \\
\text { the professional role }\end{array}$ \\
\hline & $\begin{array}{l}\text { Being creative and getting varia- } \\
\text { tion at work }\end{array}$ \\
\hline \multirow[t]{2}{*}{ Seeing one's symptoms } & Accepting one's symptoms \\
\hline & Managing one's symptoms \\
\hline
\end{tabular}

Concern for the customers was important for the hairdressers, while in turn, colleagues and customers were important for the comfort and well-being of the hairdressers. There could also be difficulties in discussing serious financial matters such as the cost of preventive measures in the premises with colleagues who were also one's friends. Preventive actions could be important, but were not always carried out due to the lack of knowledge or funds. A change in products used in the salon could be one way of improving the work environment and also of caring for the customer. Better products such as those containing less harmful hair chemicals were desired, and a conscious effort to introduce organic products was made in some salons. Having respiratory or skin symptoms contributed to the hairdressers' desire to change products.

"Nothing will happen, it feels as though nothing came of those things, it was just talking, and being as everything was between friends so nothing came of it, ..." (Ip 11)

\section{2) Applying knowledge}

The informants spoke of the importance of using preventive measures at work in the same way as had been done during their training. Those who had recently qualified and started to work in salons used strategies that included either accepting and applying the way their colleagues worked, or trying to implement the knowledge gained during their training. This would be applied to a greater extent when good routines had been the norm during their education. Teachers had either been persistent in encouraging students to use preventive measures and thus in implementing an awareness of the work environment, 
or had practiced a laissez-faire mentality, allowing the students to take this responsibility themselves. The importance of the role of teachers in training was thus evident.

The primary focus at the beginning of the hairdressers' careers was on training and application of techniques, and preventive work was given second place. However, practicing good routines from a work environmental perspective depended on a number of factors, such as colleagues, one's own knowledge, routines learnt during training and existing symptoms. The hairdressers' awareness of the preventive work would be put into practice to a greater extent if they started a business of their own in new premises, which thus gave them the opportunity to realize their visions. Furthermore, their search for more knowledge would increase in this type of situation.

"Yes, because this business with the work environment and safety as it's called is so much more than we had at school. Oh, of course we had hair dryers that hung from the ceiling, but we never discussed why. That is why it was so, why it was important that it was this way or that way." (Ip 2)

\section{3) Planning work}

The awareness of planning of the work in salons varied, and it was not always possible for the hairdressers to carry it out the way they wanted to. The responsibility of being self-employed or renting a chair in a salon was sometimes felt as being heavy for the young businesswomen and could in some cases lead to stress. On the other hand, this could be an advantage in terms of planning one's schedule or time off. There was also a desire to be employed in order to avoid having such responsibility at the beginning of their careers. Moving directly from a school environment and living with one's parents to being on one's own both in business, and maybe in one's personal life, could be seen as a major step to take. However, a desire to start one's own business and to have the possibility of designing the salon and the way work is done was also expressed, which could thus provide an opportunity to work in a preventive manner. The hairdressers' colleagues in the salon were important for the planning of the work. Planning work schedules together could be of importance, but this was something that was not made visible at the work place. Issues concerning prevention were seldom discussed at meetings in salons. The work situation in salons where several hairdressers worked could be tiring due to the level of noise, odors and heat generated by there being many hairdressers and clients in a confined space at one time. Financial awareness and responsibility for the business were influential factors throughout the planning process, affecting the customer timetable, purchases, and relationship with and competition among colleagues and other salons.

"I think that you should be able to sit down, and you have to be able to eat etc. That's important because otherwise you won't manage it. There are those who work nonstop and then you don't feel well in the evening when you get home" (Ip 3)

\section{Seeing one's customers}

The customers had an influential position in that they were the foundation of the business, and the hairdressers were aware of the need for the customers to be satisfied with their work; this was seen in their desire for it to be so. It was thus important to care about the customers, who were also important in social terms. This awareness was described as adjusting to the customer's needs and as caring for the customer.

1) Adjusting to the customer's needs

The priority was to make it easy and to provide good value for the customers of the salon. To provide good value, the hairdressers were prepared to make compromises in e.g. scheduling, and to give way and push themselves further for regulars. Price could also be significant for the business but were dependent on the situation of the salon. Financial issues could thus impact the business, and putting themselves first and the clients second could lead to some stress if the hairdressers, for example, chose to use scheduling to create some freedom for themselves.

"I can stand here. Now this is my third 12-hour day this week. Oh, but I only have one haircutting per hour, partly because I want to do a proper job and partly because I appreciate a 15-minute break between each customer, and then I don't feel the same stress. At the same time, so I don't earn as much money ....." (Ip 14)

\section{2) Caring for the customer}

Being available to meet the customer's needs was essential, and giving them priority was the norm. This could lead to stress for the hairdressers, for example, by having two parallel appointments. Similarly, caring for the customer could lead to stress if the hairdresser was not able to keep the appointment times. Good communication and good strategies to manage such situations were thus indispensable. Providing refreshments in the salon could be important in certain situations, thus making the customers feel cared for, as could having products to sell that the individual hairdresser could recommend. However, the strategies could vary, and the organization of the salon could be the determining factor for the choice of strategy. 
"...I have a little experience of other hairdressers who push in as much as possible in as short a time as possible and do it carelessly and stress themselves, and I don't want to do that. Instead I always have my usuals if there isn't anything very special, because I want to give to the customer and be relaxed myself." (Ip 12)

\section{Seeing one's profession}

There was an awareness of the advantages and the disadvantages in the profession and what that could lead to in the future, which could be somewhat insecure if symptoms had already occurred after three to four years of being a hairdresser. The hairdressers took pride in their profession and wanted to do a good job-it was the work they liked and wanted to continue doing. Perfectionism was not uncommon among the hairdressers, which affected them and could increase the risk of stress. Seeing one's profession was described as developing and continuing in the professional role and being creative and getting variation at work.

1) Developing and continuing in the professional role

The hairdressers expressed a desire to attend courses in order to create a niche for themselves or to be able to become a mentor for colleagues. Anxiety due to the fact that they caused themselves to be vulnerable to medical or psychological symptoms led to some of them desiring to develop themselves further, to create new concepts or to specialize within a field such as hair arrangements for weddings or teaching. There was also an element of being wise about the disadvantages of the profession. The expectations and the possibilities for the future varied either in terms of the level of acceptance of not being able to work more than about ten years, or in terms of finding different solutions to make it possible to stay in the profession the whole of their working lives.

“...Oh, partly because I'll start to think it's boring. I'll always enjoy the contact with the customers, but I think I'll think it's boring. And if I consider my health, the allergy has deteriorated noticeably the last year, so it doesn't have to do with this, but there are many reasons for me to think that my work can make me weaker, which leads me to see that I don't want to be doing this perhaps in ten years time ...." (Ip 14)

2) Being creative and getting variation at work

Creativity was a major element in hairdressing, and the profession provided a number of opportunities for being creative or for finding a new vocation. Being self-employed entailed having a responsibility for the business, with the more "glamorous" work elements concerning hair combined with other more menial duties such as cleaning, ordering products, reception and financial work. All these duties also generated a variation within the profession.

"Thus when the customers are satisfied, when you see that you have really, that you've done something to make another person happy, absolutely, it's the best. ... I think most of it is enjoyable actually. I think it's good that there is variation. I wouldn't like to be with one who only cuts for example ...." (Ip 6)

\section{Seeing one's symptoms}

The informants described symptoms such as headaches, tiredness, nose blocks, nasal secretion, throat irritation, shortness of breath, coughs, watery eyes, skin irritation that even generates pain, and musculoskeletal stress and pain varying from mild to severe discomfort. Tiredness often accompanied the other symptoms. Headaches could be caused when the air was filled with chemicals, scents and odors and there were high noise levels due to large numbers of clients and hairdressers being in the same premises at the same time. The effect on their quality of life appeared mostly as tiredness, but sleep was also affected. Preventive measures to reduce symptoms were mostly focused on the skin and the musculoskeletal system and consisted of the use of good products, gloves, physical training, and even regular massages. Seeing one's symptoms was described as accepting one's symptoms and managing one's symptoms.

1) Accepting one's symptoms

There was a large acceptance of the work situation as such by the hairdressers, who could feel anxiety about symptoms and their prognosis if they continued their work in a salon. However, it was still not common for them to find means and strategies to prevent the symptoms, except for minor steps like use of gloves or physical training. Having symptoms also implied feeling some stress vis-à-vis the clients and the work and could sometimes be associated with a stressful period of work. The quality of life of the hairdressers was impacted by work-related symptoms, but they were not always aware of the connection between the symptoms and the constraints on their daily lives.

"I've thought about changing my job, but I don't know what I'd do otherwise. So I'll carry on. I've thought that it's been quite difficult with my hands and always having problems and pain with that. But then I don't know what I'd do instead, and thus I carry on." (Ip 8)

2) Managing one's symptoms

Changes in the work environment, such as a change in the use of hair products, a change of salon, a 
change in planning work, a change in time off and a change in the number of colleagues working at the same time, had an impact on the symptoms. The approach of colleagues could vary greatly from being very understanding to making fun of the hairdresser with symptoms. The strategies for dealing with the symptoms varied from doing nothing to actually trying to adjust the work environment in a correct way. The use of gloves and nasal spray were easy ways of managing symptoms of the skin and the nose.

"Yes the days when it's hot outside and both of us are working a lot with dyeing and chemical treatments, then we become very tired and feel it in our throats and bodies, and it's not good to stand like that. And then we go out and call attention to the ventilation, but it's not always possible to rectify it." (Ip 11)

\section{Managing one's waste}

Managing waste included different alternatives for the hairdressers, from just sorting the domestic waste into paper, metals and plastics to sorting hair dye and bleaching powder remnants from the rest and leaving it at a waste disposal site. The possibility of buying this service from an entrepreneur who could collect the sorted waste was rarely utilized, but some owners took the sorted waste to the disposal site themselves, while others were not very concerned as to what happened with the waste. Rinsing hair dye, bleaching powder, high lightening and other hair products into the ordinary sewage system without using any additional filter was common. Initiatives to get information from the environmental administration of the municipal authorities had been taken, but without results. Good routines were important for managing waste, and some of the hairdressers expressed that it would be easy to adjust but that they had not given it much consideration. If fixed routines had been available, they would have followed them, but seeing the needs and implementing the routines had not been self-evident. There were, however, hairdressers who were aware and actively adhered to good working routines to diminish the waste of hair chemicals etc. The greatest responsibility for waste products was taken by the owner of the salon, but when renting a chair in a salon, such a responsibility did not seem obvious. The issue was seldom discussed among the colleagues. Suitable working techniques were also a way of coping with waste products when, for example, hair dyes and bleaching powder were mixed in smaller quantities several times instead of having to pour out leftover materials. The management of waste products was also a financial issue.

"....but there were no regulations for that, which surprised me a little. I would have thought that it would be particularly suitable for all hairdressers to have something in the drain. Waste that can be burnt, that perhaps doesn't matter, but there's so much else that is, or well, doesn't matter and doesn't matter. But I think that there's so much more that is just as dangerous, but I don't really think that it's good just to flush everything down as we do,...” (Ip 12)

\section{Discussion}

\section{Methodological aspects}

There was a small number of participants in this study due to the outcome of the original study. Ten hairdressers declined to participate because of travelling abroad or too much work. This could have affected the findings in that those who claimed they had too great a work load to participate could have perceived more stress at work. We chose to have participants both with and without respiratory symptoms, as our aim was to discover if there were differences in how they perceived and reflected upon the work environment. No differences were found when reading the interviews, and the decision was made to analyze all the interviews together. Hairdressers without respiratory symptoms in the original project could, at the time of the interviews, have had other work-related symptoms that affected them, just as those hairdressers who had respiratory symptoms also had other symptoms. The interviews were performed either in participants' homes or salons. As the participants were able to make this choice themselves, we do not believe that the place where the interview took place had any influence on the results, as they were comfortable in the situation.

The present study was designed and written in accordance with the consolidated criteria for reporting qualitative research, COREQ ${ }^{18)}$. The methodology in this study is thus thoroughly described, which contributes to its credibility. The researchers' pre-understanding might, however, have influenced the interviews and the data analysis. In the interview situation, the interaction between the interviewer and the informant may influence the outcome. According to Malterud, "personal issues can be valuable sources for relevant and specific research", and the perspective of the researcher always shapes the research ${ }^{19)}$. In the present study the researchers' pre-understanding was important in terms of being able to ask questions that were well-grounded in the field, and this was also taken into account and reflected upon during the analysis. The interviews were read by the third author in order to provide feedback to the interviewer as a support for developing interview skills in order to increase the trustworthiness of the data and the findings. To further improve the trustworthiness, the 
second author, who had not previously participated in the study, read a number of interviews and agreed on the themes and the subthemes. The participants did not have this opportunity, which could be a disadvantage, but the inclusion of relevant quotations from the transcribed text enhanced the trustworthiness of the findings ${ }^{17)}$.

The use of qualitative content analysis can be criticized, but the advantage of the conventional approach to content analysis is the ability to gain direct information from the participants without imposing preconceived categories or theoretical perspectives. This was found to agree well with the aim of this study. This method has been described as being useful in gaining information based on the participants' unique perspectives grounded in the data, thus allowing the researcher to get a broader understanding of the phenomenon $^{16)}$. We found it the most suitable method to gain information from the participants for our study.

\section{Main findings}

The overall findings indicate that the hairdressers were aware of their work environment, but not of all the possible measures to prevent illness. There was a focus on the working techniques and the impression the salon gave but not on the possibility of using the work environment as a way to market the salon and care about the clients. The possibilities of influencing the work environment differed due to the organization of the salon, financial reasons or lack of knowledge. The hairdressers thus constitute a professional group, who largely accept their work environment as it is, and this may be due to experiences of positive elements in the profession ${ }^{15}$.

The level of awareness of the work environment varied with regard to the different parts of the work environment. Most hairdressers in Sweden are selfemployed and do not have large financial margins, and thus investment in an air extraction system could well be beyond their means. Preventive measures were taken in smaller and less costly matters such as the use of gloves and aprons, choice of products, participating in sports and use of a chair, but where larger investments were necessary, it was the salons with one owner and a number of employees that were able to carry out improvements. This is, however, not specific to hairdressers in Sweden. Iwatsubo et al. found that only about half of the salons in their French study had a specific ventilated technical area ${ }^{20)}$. The organization of the salons appeared to play a crucial part as well. Managing a hairdresser salon with one or more owners, with a number of hairdressers renting a chair and perhaps one or two employed hairdressers is not a simple task. This together with the fact that the mean age of hairdressers in Sweden is 34 years $^{21)}$, and the fact that the colleagues are often friends, means that the job of taking preventive measures in terms of the work environment is something that can easily be disregarded.

The findings showed that the attitude and knowledge of the teachers during training were of great importance for the future interest in and the strategies concerning measures to improve the work environment. This interest and knowledge are factors that have an impact on the preventive measures. Perkins and Farrow found a positive association between the prevalence of skin problems and the frequent use of protective measures, suggesting a reaction to the incidence of problems instead of the use of precautions ${ }^{22}$, and Ling and Coulson also emphasized the practical aspects of hand dermatitis prevention in the hairdressing curriculum ${ }^{23)}$. The schools and the teachers should put greater efforts into developing the awareness of the work environment for the students and into reminding them constantly throughout their training/internship. Hairdressers thus need to be constantly reminded of the importance of preventive measures by teachers and colleagues in order to increase their awareness of the work environment.

That the foundation for the hairdressing profession is the customers was evident in the findings, and customer comfort and satisfaction were the main priorities. The hairdresser herself, her health and her well-being were more or less neglected where the customers were concerned, in particular in the case of the regulars. This could be due to financial reasons, ignorance or a lack of interest in one's own health. The core of regulars was treated with special care, as there was a need to have them in order to keep the business solvent. The focus on the satisfaction of the customer could lead to stress for the hairdressers, and mental strain and a large number of customers have been seen to increase work-related upper limb disorders in hairdressers ${ }^{24)}$. The social impact of the customers as a positive element for the hairdressers should, however, not be ignored, and caring for the customer would increase this ${ }^{15)}$. It would be of great value for the hairdressers to see the connection between a healthy work environment and a satisfied customer from an occupational health perspective. A hairdresser who does not feel well due to her work is not good publicity for the salon, and customers today have become more aware of the chemicals used in hairdressing salons and have expressed worries and questions about the health effects of these chemicals. The high number of hairdresser salons in Sweden generates fierce competition between salons ${ }^{11)}$. This might lead to the work environment being ignored because of the need to fill the time schedule to keep the business financially solvent. The competition 
could be coped with by increasing the awareness of the work environment instead, which could also form the foundation for good marketing for the hair salons.

Little discussion took place among hairdressing colleagues about the work environment, and no forum for the hairdressers to debate and to get help in finding knowledge, strategies and manageable solutions has been established in Sweden. Many young hairdressers are not members of an organization for hairdressing businesses or union, as they see this as being too costly, and are not aware of the possibilities that occupational health can offer them ${ }^{11)}$. The SWEA performed inspections in hairdresser salons in Southern Sweden in 2011, and more than 870 working sites, including nail builders and schools, were visited. This inspection increased the awareness of the work environment, the safety risks and the regulations among the hairdressers. It also increased the knowledge of how to improve the work with the occupational environment. However, the SWEA stated that the hairdressers had knowledge of the chemicals used in hairdressing salons and also ergonomic issues, but that this knowledge was not always implemented. Furthermore, the SWEA reported that the information from the Swedish Cosmetic, Toiletry and Detergent Association and their safety instructions were not widely read ${ }^{11}$. This concurs with the findings from an English study, in which it was found that most hairdressers used information from labels on chemical products to assist product preparation and to determine whether the product would suit a particular client, but not for eventual health risk information ${ }^{25}$. The present study suggests the need for frequent inspections to stimulate interest and awareness in the profession with regard to existing regulations, which is an important issue for the authorities to deal with. It thus indicates that greater knowledge and help for small business premises would be important.

That the hairdresser profession has both advantages and disadvantages became evident in this study, but an insecure future was also noticeable in terms of the number of occupational health risks. Pride in the profession was expressed together with its many positive elements, such as the possibility of developing within the profession, independence, social context and creativity. The possibility of developing within the profession might constitute a strategy to cope with health issues and to avoid exposure to occupational risks but also constitutes a desire to become more skilled and educated in order to be able to find one's own niche within the hairdressing profession. Being a small entrepreneur was positive in terms of independence, but could also be stressful regarding financial issues and giving clients priority, which could increase symptoms. The flexibility and possibility of control- ling one's working hours, which are elements of the independence in the profession, could be important factors in positively affecting health and well-being, as was also found by Costa et al. ${ }^{26)}$. Hairdressers are part of a social context together with their clients, which is important for them. A study of small-scale entrepreneurs showed an association between good self-reported health and a good social life ${ }^{27)}$, and in an earlier qualitative study, we found that the social interaction with the clients is something that is very meaningful for hairdressers ${ }^{15}$. Creativity is a basic element in hairdressing, and offers opportunities to the hairdressers to find ways to vary their work or even to find other approaches if leaving the profession. The latter contains many positive elements, but there is at the same time a need for preventive measures in the work environment to reduce health risks; a strong awareness of this among the hairdressers is essential.

\section{Conclusions and implications}

This qualitative study showed that hairdressers are aware of their work environment, but lack the means and strategies to make it an active part of their business. The main focus for hairdressers is their customers and the working techniques within hairdressing. Having various symptoms did not alter this, and hairdressers with respiratory symptoms in the original project could have other physical symptoms at the time of the interview as was the case for the hairdressers, who in the original project did not have respiratory symptoms. We have also found that schools and teachers have a crucial role in making the work environment be as interesting an issue as the hairdressing techniques are, and that organization or financial issues could impact the work environment negatively. The occupation of hairdressing could be seen to have advantages and disadvantages, but also its future as insecure in terms of the occupational health risks and their consequences; there was, however, a great pride in the profession providing opportunities for development.

It would be of value for hairdressers to have a forum where they could gain information and have the possibility of discussing issues concerning the work environment. The role of the customer as the foundation for the business makes it necessary for the profession to see the customer and the work environment as one unit, and to integrate the work environment in the profession. It could also be of value to consider how hairdressing salons are organized, as it can be difficult to properly grasp the problem of the work environment if the management is weak.

Appropriate health education and risk assessment are important for hairdressing students if we are to see a reduction of occupational illnesses in the profes- 
sion. Measures and initiatives taken by the responsible authorities would also be a way to increase knowledge and to inform the hairdressers of the existing regulations. It is also important that suppliers use fewer chemicals in their products, while retaining the qualities that the customers desire so that the hairdresser and the customer will both be satisfied with the result. The work environment should be given greater consideration than is done at present in order for it to be an important factor in the hairdresser's working life.

Acknowledgments: We thank all the participating hairdressers for sharing their experiences with us. We are grateful to Gudrun Persson who transcribed the interviews and to Professor David Brunt for the English revision. The study was carried out at the Department of Occupational and Environmental Medicine, Laboratory Medicine, Lund, Sweden.

\section{References}

1) Albin M, Rylander L, Mikoczy $Z$, et al. Incidence of asthma in female Swedish hairdressers. Occup Environ Med 2002; 59: 119-23.

2) Brisman J, Albin M, Rylander $L$, et al. The incidence of respiratory symptoms in female Swedish hairdressers. Am J Ind Med 2003; 44: 673-8.

3) Kronholm Diab K, Truedsson L, Albin M, Nielsen J. Persulphate challenge in female hairdressers with nasal hyperreactivity suggests immune cell, but no IgE reaction. Int Arch Occup Environ Health 2009; 82: 771-7.

4) Kronholm Diab K, Jönsson BA, Axmon A, Nielsen J. Work related airway symptoms, nasal reactivity, and health related quality of life in female hairdressers: a follow-up study during exposure. Int Arch Occup Environ Health 2014; 87: 61-71.

5) Lind ML, Albin M, Brisman $J$, et al. Incidence of hand eczema in female Swedish hairdressers. Occup Environ Med 2007; 64: 191-5.

6) Lind ML, Boman A, Sollenberg J, Johnsson S, Hagelthorn G, Meding B. Occupational dermal exposure to permanent hair dyes among hairdressers. Ann Occup Hyg 2005; 49: 473-80.

7) Rylander L, Axmon A, Torén K, Albin M. Reproductive outcome among female hairdressers. Occup Environ Med 2002; 59: 517-22.

8) Axmon A, Rylander L, Lillienberg L, Albin MLH. Fertility among female hairdressers. Scand J Work Environ Health 2006; 32: 51-60.

9) Axmon A, Rylander L. Birth weight and fetal growth in infants born to female hairdressers and their sisters. Occup Environ Med 2009; 66: 198-204.

10) Arbetsmiljöverket Efs, 11279 Stockholm. Frisörer och hudterapeuter; Hairdressers and esthetucians. Korta arbetsskadefakta; Short Work Injury Facts 2010 (10).

11) Arbetsmiljöverket. Frisörer och nagelbyggare—en regional tillsynsinsats genomförd avArbetsmiljöverket i södra Sverige 2011; Hairdressers and nail builders - a regional supervision effort made by the Swedish Work Environment Authority in Southern Sweden 2011. 2012 (Rapport 6).

12) SCB SS. Yrkesgrupper med besvär av arbete 2010. Andel (\%) av alla sysselsatta som har besvär av arbete och könsfördelning (\%) bland sysselsatta. Occupational groups with work related symptoms 2010. Proportion of all employed with work related symptoms and sex distribution (\%) among employed. 2010.

13) Bradshaw L, Harris-Roberts J, Bowen J, Rahman SDF. Self-reported work-related symptoms in hairdressers. Occup Med (Lond) 2011; 61: 328-34.

14) Berg B. Qualitative research methods for the social sciences. Boston (MA): Allyn and Bacon; 2004.

15) Kronholm Diab K. Hur påverkar överkänslighet mot blekmedel kvinnliga frisörers hälsa och livskvalitet (How does hypersensitivity to bleaching powder affect the health and the quality of life female hairdressers). Lund Lund University, 2002.

16) Hsieh HF, Shannon SE. Three approaches to qualitative content analysis. Qual Health Res 2005; 15: 1277-88.

17) Graneheim U, Lundman B. Qualitative content analysis in nursing research: concepts, procedures and measures to achieve trustworthiness. Nurse Education Today 2004; 24: 105-12.

18) Tong A, Sainsbury P, Craig J. Consolidated criteria for reporting qualitative research (COREQ): a 32-item checklist for interviews and focus groups. Int J Qual Health Care 2007; 19: 349-57.

19) Malterud K. Qualitative research: standards, challenges, and guidelines. Lancet 2001; 35: 483-8.

20) Iwatsubo $Y$, Matrat M, Brochard $P$, et al. Healthy worker effect and changes in respiratory symptoms and lung function in hairdressing apprentices. Occup Environ Med 2003; 60: 831-40.

21) SCB SS. The occupational structure in Sweden 2010-Occupational statistics based on the Swedish occupational register. Employed persons aged 16-64 years by occupation, sex and average age, 2010. [Online]. 2012 [cited 2013 Jul 8]; Available from: URL: http://wwwscbse/Statistik/AM/AM0208/ 2010A01/AM0208_2010A01_SM_AM33SM1201pdf

22) Perkins J, Farrow A. Prevalence of occupational hand dermatitis in UK hairdressers. Int J Occup Environ Health 2005; 11: 289-93.

23) Ling T, Coulson I. What do trainee hairdressers know about hand dermatitis? Contact Dermatitis 2002; 47: 227-31.

24) De Smet E, Germeys F, De Smet L. Prevalence of work related upper limb disorders in hairdressers: a cross sectional study on the influence of working conditions and psychological, ergonomic and physical factors. Work 2009; 34: 325-30.

25) Bradshaw L, Harris-Roberts J, Bowen J, Rahman S, Fishwick D. Self-reported work-related symptoms in hairdressers. Occupational Medicine 2011; 61: 328-34. 
26) Costa G, Sartori S, Akerstedt T. Influence of flexibility and variability of working hours on health and well-being. Chronobiol Int 2006; 23: 1125-37.

27) Gunnarsson K, Josephson M. Entrepreneurs' self- reported health, social life, and strategies for maintaining good health. J Occup Health 2011; 53: 205-13. Epub 2011 Mar 16. 